\title{
Potentialities of legumes in the pharmaceutical industry
}

\begin{abstract}
Legumes are part of a group of foods widely used in human and animal food since the earliest times because of their high nutritional value, being important sources of proteins, carbohydrates, fibers, minerals and vitamins. In addition, its composition also presents several bioactive compounds, which have been associated with the prevention of several diseases, especially those related to the cardiovascular system. Another aspect to be observed is that some of its biochemical characteristics, such as the type of starch, protein and fibers, can be exploited as binders, excipients, thickeners and dispersants in the formulation of various pharmaceutical products in the pharmaceutical industry. Thus, this review article raised the need to evaluate the potential of legumes in this industry through the analysis of the different works carried out and available in the literature.
\end{abstract}

Volume 7 Issue 3 - 2018

\section{Clicia Maria de Jesus Benevides, Bruna Almeida Trindade, Mariângela Vieira Lopes Department of Life Sciences, State University of State Bahia- UNEB, Brazil}

Correspondence: Clicia Maria de Jesus Benevides, Department of Life Sciences, Nutrition Course. University of State Bahia, Salvador- Bahia-Brazil,Tel +55-7I-9877589/4, Email cbenevides@uneb.br

Received: May 14, 2018 | Published: June 26, 2018

Keywords: legumes, biative compounds, pharmaceutical industry

Abbreviations: PUFAs, polyunsaturated fatty acids; DPPH, 2,2-diphenyl-1-picryhydrazyl; FRAP, ferric reducing antioxidant power; ORAC, oxygen radical absorbance capacity; HPLC, high performance liquid chromatography; MS, mass spectroscopy; NMR, nuclear magnetic resonance; CVD, cardiovascular disease; CHD, coronary heart disease; HRT, hormone replacement therapy

\section{Introduction}

The Fabaceae family, known as Leguminosae, is the third largest of angiosperms, consisting of 32 tribes whose 727 genera are chemically represented by a large diversity of flavonoid skeletons, notably pterocarpa and isoflavanone, which comprise approximately 19,325 species. ${ }^{1}$ The wealth of this family can not be attributed solely to its ecological importance and to the large number of its species distribution, but also economically, since its potential is very marked including in food, medicinal and oil varieties, besides contribute to agriculture by fixing nitrogen to soils. ${ }^{2}$ Epidemiological studies have a direct association between the prevention of some diseases and the daily intake of bioactive compounds present in certain foods. In this sense, legumes contain, besides their various nutrients, compounds such as polyphenols, soluble fiber, isoflavones, among others, which give them functional food properties, contributing to the prevention of various diseases..$^{3-5}$

Legumes and their components have become targets for research in order to observe their potential for purposes other than food, such as for research related to the pharmaceutical industry. ${ }^{6,7}$ This has been increasingly concerned with investigating new bioactive compounds to be used in drug formulations. ${ }^{8,9}$ Thus, this review aimed to evaluate the potential of legumes for use in the pharmaceutical industry, as well as its role in human nutrition and in the prevention of diseases of high prevalence in the contemporary world.

\section{Importance of legumes in food}

Our increasing population and the concomitant need to adequately feed people to prevent particular health problems will necessitate a larger dietary contribution from legumes. ${ }^{10}$ Legumes include lentils
(Lens culinaris L.), beans (Phaseolus vulgaris L.), peas (Pisum sativum L.), chickpeas (Cicer arietinum L.), lupins (Lupinus albus spp.), fava beans (Vicia faba), soy beans (Glycine max) and others. Cultivated for thousands of years, they have played an important role in the traditional diets of many regions throughout the world. ${ }^{11,12}$

Legumes are among the most important sources of protein, starch and dietary fiber. These cultures contain on average 18.5-30\% protein, $32-52 \%$ starch and $14.6-26.3 \%$ dietary fiber, ${ }^{13}$ as well as rich in vitamins like niacin, riboflavin and thiamine and minerals such as calcium, iron, potassium manganese and zinc, ${ }^{14,15}$ and phytochemicals such as phenolic acids, flavonoids and proanthocyanidins. ${ }^{16,17}$ In addition, they are low in fat (with the exception of oil seeds). ${ }^{18}$ In this way, they are considered of extreme importance for human food, making possible the obtainment of a nutritionally rich and healthy diet. $^{19}$

Although legumes have large amounts of protein, they do not all contain essential amino acids, since they are deficient in sulfur amino acids. Thus, the diet requires other foods, such as cereals to supplement these deficiencies, ${ }^{20}$ providing a better balance of the essential amino acids. ${ }^{21,22}$ As the legume group is an important source of lipids, mainly oilseeds, and fatty acids in animal and human nutition, the fatty acids contents in legumes has been studied ${ }^{23,24}$ and it is reported that most of the legume seeds are poor in fatty acids with the exception of soya bean. ${ }^{25}$

Caprioli et al., ${ }^{26}$ investigated the lipid profile of 19 leguminous plants and obtained the AG C16:0, C18:1, C18:2, C18:3 for three different species of $P$. vulgaris that varied from 7.5 to $18.5 \% ; 8.8$ to $17.2 \%, 23.4$ to $31.5 \%, 29.4$ to $43.6 \%)$ and to $V$. faba $(14.7 \%$, $32.4 \%, 47.1 \%, 3,4 \%$ ), respectively. The nutritional potential of nine underutilized leguminous crops in southwestern Nigeria was also studied by Ade-Omowaye et al. ${ }^{27}$ who found the AG C16:0, C18:1, C18:2, C18:3, respectively, for Cajanus cajan $(21.59 \%, 10.21 \%$, $49.69 \%$, 4.66\%); Vigna racemosa $(9.87 \%, 34.59 \%, 29.62 \%, 4.92 \%)$ and Vigna subterranean $(21.09 \%, 17.01 \%, 43.06 \%, 2.61 \%)$. The composition of AG (16:0, C18:1, C18:2, C18:3) of the oil of three cultivars of Vicia faba varied from:Vicia faba cultivar Sudan $(15.75 \%$, 
$30.79 \%, 46.41 \%, 2.76 \%$ ); Vicia faba var, major cultivar, white Windson $(18.3 \%, 18.0 \%, 28.3 \%, 3.6)$; Vicia faba var, minor cultivar, "Nadwislanski (19.2\%, 18.4\%, 30.8\%, 4.3\%) respectively. ${ }^{28}$

Although the lipid content of beans is generally low, regular intake may contribute significantly to obtaining dietary recommendations on the quantity and quality of fat, ${ }^{29}$ contributing to reduce the risk of development of various chronic diseases such as cardiovascular diseases, various digestive disorders and cancer, as well as arthritis and inflammation. ${ }^{30-32}$ Polyunsaturated fatty acids (PUFAs) function as constituents of cell membranes and precursors of various signal molecules..$^{33,34}$ They are important in both the medical and pharmaceutical fields, as they are involved in the human inflammatory response, blood-pressure regulation, cholesterol metabolism, and infant retinal and brain development. ${ }^{35}$

A number of inorganic minerals are important either in the structure or functioning of the body and must, therefore, be provided by the various components that make up the diet. ${ }^{36}$ Legumes, individually or as composite, are extensively used to prepare complementary and family foods in developing countries. ${ }^{37}$ Common beans contain relatively high concentrations of iron $(\mathrm{Fe})$ and zinc $(\mathrm{Zn})$ but are also high in polyphenols and phytates, factors that may inhibit $\mathrm{Fe}$ and $\mathrm{Zn}$ absorption. ${ }^{38}$ Mawani et al., ${ }^{39}$ report that iron deficiency anemia is one of the important public health problems in developing countries among the women of reproductive age group. In developing countries, cereals and pulses/legumes are used as staple foods and are a good source of micronutrients with high levels of ionizable Fe. However, the bioavailability of zinc was low in cereals compared to pulses. ${ }^{40}$

\section{Bioactive components of vegetables}

Integrative and complementary practices in health are regulated as therapeutic resources, mainly with the use of medicinal plants associated with food.$^{41}$ Some phytochemicals present in these plants can intervene in a beneficial way in human health, protecting or aiding in the treatment of various diseases. ${ }^{42,43}$ Pulses contain several components with bioactive properties, including fibres, polyphenols, and protein fractions. The cardio-protective effect of dietary pulses is partially explained by the high content of viscous soluble fibres in these foods. ${ }^{44}$

Pulses provide significant quantities of bioactive phytochemicals such as phenolic acids, carotenoids, and tocopherols, which may protect LDL-C from free radical oxidation. ${ }^{32,45}$ Recently, 14polyphenols were identified by HPLC-DAD in cultivars of beans, chickpeas, lentils, and field pea; these included: gallic acid; the anthocyanin glycosides delphinidin 3, 5-diglucoside and cyanidin-3-glucoside; chlorogenic acid; the flavanols $(+)$ - catechin and $(+)$ - epicatechin; caffeic acid; syringic acid; rutin; p-coumaric acid; kaempferol 3-glucoside; ferulic acid; resveratrol; and, quercetin. ${ }^{46}$ Garcia-Lafuente et al., ${ }^{47}$ observed a direct association between the content of phenolic compounds in the bean extract and its antioxidant capacity, demonstrating the importance of the phenolic compounds as bioactive compounds of the beans.

The major polyphenolic compounds of pulses consist mainly of tannins, phenolic acids and flavonoids. Pulses vary based on their total phenolic contents and antioxidant activities. Lentils have the highest phenolic, flavonoid and condensed tannin content $(6.56 \mathrm{mg}$ gallic acid equivalents $\mathrm{g}^{-1}, 1.30$ and $5.97 \mathrm{mg}$ catechin equivalents $\mathrm{g}^{-1}$, respectively), followed by red kidney and black beans. ${ }^{48}$ According to literature, total phenolic content is directly associated with antioxidant activity ${ }^{49,50}$ Pulses with the highest total phenolic content (lentil, red kidney, and black beans) exert the highest antioxidant capacity assessed by 2,2-diphenyl-1-picryhydrazyl (DPPH) free radical scavenging, ferric reducing antioxidant power (FRAP), and the oxygen radical absorbance capacity (ORAC).$^{48}$

The composition of polyphenols in chickpeas varied widely by cultivar, but was dominated by catechin. Split green peas were found to contain mostly syringic acid, followed by smaller quantities of courmaric acid and ferulic acid. ${ }^{46}$ Flavones and isoflavones have been isolated from a wide variety of plants, though the isoflavones are largely reported from the Fabaceae/Leguminosae family. Chickpeas contain daidzein, genistein, and formononetin $(0.04,0.06$, and $0.14 \mathrm{mg}$

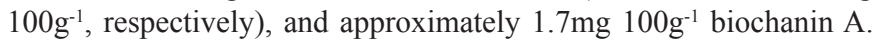
Soybeans have significantly higher levels of daidzein and genistein

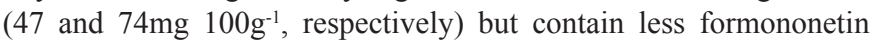

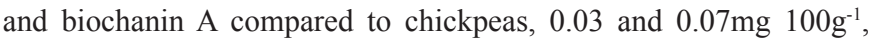
respectively. There are many biological activities associated with the isoflavones, including a reduction in osteoporosis, cardiovascular disease, prevention of cancer and for the treatment of menopause symptoms. ${ }^{51,52}$

Legumes also provide precious micronutrients, such as tocopherols, i.e. vitamin E. Tocopherols behave as potent antioxidants, since they are able to interrupt the chain reactions that are responsible for the peroxidation of unsaturated lipids, by trapping hydroperoxide intermediates. ${ }^{53}$ In the some legumes, such as chickpea, soybean and broad bean, provide relevant levels of the major contributor to vitamin E activity, i.e. $\alpha-T$. By contrast, g-T is the most abundant congener in all legumes. ${ }^{54}$ Polyphenols, tocopherols, and carotenoids account for the antioxidant capacity of pulses, and in vitro free radical scavenging activity has been demonstrated for several varieties of beans, lentils, chickpeas, and peas. ${ }^{55,56}$ Pulses are good source of minor compounds which may have important metabolic and/or physiological effects and provides potential impact on health. So these compounds are currently marketed as functional foods and nutraceutical ingredients.

\section{Legumes add their pharmaceutical and health benefits}

There is a strong consumer-driven trend for natural products in the USA and Europe. Many consumers want natural drugs, believing that the natural drugs are safer than synthetics. Herbs (including many legumes) that possess anti-cancer or penile potency properties are the focus of smuggling into markets into Europe, Japan and the USA. ${ }^{57}$ Advances in analytical chemical techniques, such as high performance liquid chromatography (HPLC), mass spectroscopy (MS), and nuclear magnetic resonance (NMR) allow the rapid identification of novel compounds that are increasing the value of legumes, in particular, to the pharmaceutical industry.

Legumes contain many health-promoting components, such as fibre, proteins, resistant starch, minerals, and numerous phytochemicals endowed with useful biological activities. Hydrophilic phytochemicals, such as ascorbic acid, phenolic acids and polyphenols, have been associated with an enhancement of the immune system functionality and reduced cancer risk, whereas lipophilic phytonutrients, such as carotenoids and tocopherols, may prevent the risk of cardiovascular diseases and some eye pathologies..$^{58}$ 
Studies have shown a positive association between the consumption of pulses such as beans and the reduction of cardiovascular disease (CVD), glycemic control and diabetes, and the reduction of the risk of pancreatic, kidney and breast cancer. ${ }^{14,59}$ Aguilera et al. ${ }^{60}$ reported associations between the dietary intake of phenolic compounds, especially flavonoids, and the reduction of the risk of cardiovascular diseases.

Legume consumption of four times or more per week compared with less than once a week, was associated with $22 \%$ lower risk of coronary heart disease (CHD), and 11\% lower risk of CVD. ${ }^{61,62}$ The mechanism underlying this cardio-protective effect appears to be related to the ability of pulse legumes to attenuate total cholesterol and LDL-C. However, the evidence available to date suggests consuming a diet enriched with whole pulses results in a significant and clinically meaningful reduction in total cholesterol and LDL-C, supporting a role for dietary pulses in the management and prevention of CVD. ${ }^{56}$ The phytochemicals from legumes may be responsible for the beneficial cardiovascular effects since data from the Nurses. Health Study showed that folate and vitamin B6, from diet and supplements, conferred protection against coronary heart disease. ${ }^{63}$

Yao et al. ${ }^{64}$ verified the relationship between the components of five bean varieties and different diseases and concluded that Xiaoqu 7110 beans had the highest phenolic acid content and higher antioxidant capacity compared to the other beans tested. However, the Jiheilv 27-3 variety showed the highest antidiabetic activity, through inhibition of $\alpha$-glycosidase and advanced glycation end products. Epidemiological studies strongly support the suggestion that high intakes of whole-grain foods protect against the development of type II diabetes mellitus (T2DM) by its antioxidant effect. ${ }^{14} \mathrm{~A}$ substantial increase in dietary intake of legumes as replacement food for more rapidly digested carbohydrate might therefore be expected to improve glycaemic control and thus reduce incident diabetes. ${ }^{65}$

Some study has associated the ingestion of legumes with the reduction of different types of cancer. A reduced breast cancer risk was associated with higher intake of legumes ${ }^{66}$ and was suggest that a diet high in whole grains (including legumes), fruits and vegetables may reduce the risk of colon cancer in women. ${ }^{67}$ Agurs-Collins et al., ${ }^{68}$ revealed that consumption of legumes such as dried beans, split peas, or lentils was negatively associated with risk of colorectal adenoma.

The Vicia Fava It is rich in tyramine and also contains the alkaloids vicine and convicine which can induce hemolytic anemia in patients deficient in glucose-6-phosphate dehydroganease (G6PD), ${ }^{69}$ which presents with neonatal jaundice and acute hemolytic anemia. The faba bean seedlings were used as an initial source of L-Dopa to increase dopamine (DA) concentration in the treatment of Parkinson's disease. $^{70}$ Legumes contain phytoestrogens with broad biological activities that are now being applied to humans as treatments for menopause and osteoporosis. ${ }^{71}$ Isoflavonoid (genistein, daidzein, particularly prevalent in the Fabaceae subfamily of the Leguminosae extracts are used as alternative compounds for hormone replacement therapy (HRT) for menopausal disorders. ${ }^{72}$ Many of these secondary plant compounds are frequently found in small quantities and tend to be synthesised in specialised plant cells or at specific growth stages. This makes their extraction and purification more challenging ${ }^{73}$ and yet, with the equipment now available, we are likely to see a rapid expansion of the role for legumes or their extracted compounds in human medicines. Some active principles of medicinal plants have also been studied in sickle cell disease so that they can provide greater stability to the erythrocyte, act as anti-sickness agents and improve the prognosis and health of the patients ${ }^{74,75}$ being that the pigeon bean (Cajanus cajan (L.) Millsp-Fabaceae) has been identified as an important medicinal agent that acts, minimizing some complications of sickle cell disease through the inhibition of falcization. ${ }^{74}$

Legumes also present other potentialities for use in the pharmaceutical industry, in addition to the presence of bioactive compounds associated with disease prevention. Starch from corn, in its pregelatinized form, is already used in the pharmaceutical industry as an excipient in drug formulation, especially in solid dosage forms. ${ }^{76}$ This is because it has its own characteristics $(\mathrm{pH}$, morphology, structure, moisture, size amylose/amylopectin ratio) which allow it to act as a binder, disintegrant and/or diluent. ${ }^{77}$ Pregelatinized starch can be used as a binder, diluent and/or disintegrant in solid dosage forms. ${ }^{76}$ Further research and analysis is necessary for this, as Daudt ${ }^{77}$ affirms, when studying the native pinion and realizing that it also has high levels of starch and has characteristics that approximate those of corn starch. Legumes, because they are rich in starch and protein, have properties that may be promising in their use as a binder and excipient in the formulation of various drugs in the pharmaceutical industry. ${ }^{78}$ Other components of legumes that could be further exploited for use in the pharmaceutical industry are galactomannans and xyloglucans. They are part of the group of soluble fibers and have characteristics that allow their use as emulsifiers, thickeners and dispersants. ${ }^{79,80}$

\section{Conclusion}

The review showed that legumes have great importance in the diet of people due to their contribution in the intake of the main macronutrients (proteins, carbohydrates, lipids and fibers) and micronutrients (minerals, Vit E) necessary for the proper functioning of the organism. In addition, the valuable contribution of bioactive compounds including fibres, isoflavonoid, phenolic acids and polyphenols, folate and vitamin B6, alkaloids and protein fractions in the prevention of various diseases such as cardiovascular diseases, cancer, diabetes and Parkinson's disease. It is suggested that research should also be carried out in order to better evaluate the properties of legume starch, proteins, galactomannans and xyloglucans and their use as a binder, excipient emulsifiers, thickeners and dispersants in the formulation of various drugs in the pharmaceutical industry.

\section{Acknowledgements}

None.

\section{Conflict of interest}

The author declares that there is no conflict of interest.

\section{References}

1. Lewis GP, Schrire B, Mackinder B, Look M. Legumes of the word. London, UK: Royal Botanic Gardens, Kew. 2003. p. 1-3.

2. Wojciechowski MF, Lavin M, Sanderson MJ. A phylogeny of legumes (Leguminosae) based on analysis of the plastid matk gene resolves many well-supported subclades within the family. Am J Bot. 2004;91(11):18461862.

3. Emily MT, Padhi D, Ramdath D. A review of the relationship between pulse consumption and reduction of cardiovascular disease risk factors. Journal of Functional Foods. 2017;38:635-643.

4. Afshin A, Micha R, Khatibzadeh S, et al. Consumption of nuts and legumes and risk of incident ischemic heart disease, stroke, and diabetes: A systematic review and meta-analysis. Am J Clin Nutr. 2014;100(1):278288 . 
5. Bouchenak M, Lamri-Senhadji M. Nutritional quality of legumes, and their role in cardiometabolic risk prevention: A review. J Med Food. 2013; 16(3):185-198.

6. Reid JSG, Edwards ME. Galactomannans and other cell wall storage polysaccharides in seeds. Stephen AL, editors. Food polysaccharides and their applications. New York, UK: Marcel Dekker. Inc. 1995:155-186.

7. Scherbukhin VD, Anulov OV. Legume seed galactomannans (Review). Appl Biochem Microbiol. 1999;35(3):229-244.

8. Tendências e Inovações na Indústria de Alimentos. Aditivos e Ingredientes. 2012:54-55.

9. Gouveia F. Indústria de alimentos: no caminho da inovação e de novos produtos. Inovação Uniemp. 2006;2(5):32-37.

10. Morris JB. Bio-functional legumes with nutraceutical, pharmaceutical, and industrial uses. Econ Bot. 2003;57:254-261.

11. Caprioli G, Cristalli G, Ragazzi E, et al. A preliminary matrix-assisted laser desorption/ionization time-of-flight approach for the characterization of Italian lentil varieties. Rapid Communications in Mass Spectrometry. 2010;24:2843-2848

12. Chung HJ, Liu Q, Hoover R, et al. In vitro starch digestibility, expected glycemic index, and thermal and pasting properties of flours from pea, lentil and chickpea cultivars. Food Chemistry. 2008;111:316-321.

13. Mohammed I, Ahmed AR, Senge B. Dough rheology and bread quality of wheat-chickpea flour blends. Industrial Crops and Products. 2012;36(1):196-202.

14. Messina V. Nutritional and health benefits of dried beans. Am J Clin Nutr. 2014;100(1):S437-442.

15. Campos-Vega R, Reynoso-Camacho R, Pedraza-Aboytes G, et al. Chemical composition and in vitro polysaccharide fermentation of different beans (Phaseolus vulgaris L.). J Food Sci. 2009;74(7):59-65.

16. Magalhães SCQ, Taveira M, Cabrita AR, et al. European marketable grain legume seeds: Further insigth into phenolic compounds profiles. Food Chem. 2017;215:177-184.

17. Campos-Vega R, Reynoso-Camacho R, Pedraza-Aboytes G, et al. Chemical composition and in vitro polysaccharide fermentation of different beans (Phaseolus vulgaris L.). J Food Sci. 2009;74(7):59-65.

18. Marimuthu M, Gurumoorthi P. Phytochemical screening and ft-ir studies on wild and common South Indian legumes. Asian J Pharm Clin Res. 2013;6(2):141-144.

19. Geil PB, Anderson JW. Nutrition and health implications of dry beans: A review. J Am Coll Nutr. 1994;13(6)549-558.

20. Angioloni A, Collar C. High legume-wheat matrices: an alternative to promote bread nutritional value meeting dough viscoelastic restrictions. European Food Research and Technology. 2012; 234 (2): 273-284.

21. Temba MC, Njobeh PB, Adebo AO, et al. The role of compositing cereals with legumes to alleviate protein energy malnutrition in Africa. Internation J Food Science Technol. 2016; 51(3):543-554.

22. Kadam ML, Salve RV, Mehrajfatema ZM. Development and Evaluation of Composite Flour for Missi roti /chapatti. J Food Process Technol. 2012;3(1):2-7.

23. Yoshida H, Yuka Tomiyama, Naoko Yoshida, et al. Lipid Classes.Fatty acid distribution and triacylglycerol molecular species of broad beans (Vicia faba). J Am Oil Chem Soc. 2008;85(6):535-541.

24. Jokić S, Rezica Sudar, Sandra Svilović, et al. Fatty acid composition of oil obtained from soybeans by extraction with supercritical carbon dioxide. Czech J. Food Sci. 2013;31(2):116-125.

25. Grela ER, Gunter KD. Fatty acid composition and tocopherol content of some legume seeds. Anim Feed Sci Technol. 1995;52(3-4):325-331.
26. Caprioli G, Giusti F, Ballini R, et al. Lipid nutritional value of legumes: Evaluation of different extraction methods and Determination of fatty acid composition. Food Chem. 2016;192:965-971.

27. Ade-Omowaye BIO, Tucker GA, Smetanska I. Nutritional potential of nine underexploited legumes in Southwest Nigeria. IFJR. 2015; 22(2):798-806.

28. Khalil MI, Salih MA, Mustafa AA. Study of fatty acid composition, physiochemical properties and thermal stability of broad beans (Vicia faba) seed oil. Agric Bio J N Am. 2017;8(4):141-146.

29. USDA. Dietary guidelines for Americans 2005. 6th ed. US: Department of Health and Human Services; 2005.

30. Simopoulos AP. An Increase in the Omega-6/Omega-3 fatty acid ratio increases the risk for obesity. Nutrients. 2016; 8(3):128.

31. Bouchenak M, Lamri-Senhadji M. Nutritional quality of legumes, and their role in cardiometabolic risk prevention: A review. J Med Food. 2013; 16(3):185-198.

32. Ros E, Hu FB. Consumption of plant seeds and cardiovascular health epidemiological and clinical trial evidence. Circulation. 2013;128(5):553565 .

33. Needleman P, Turk J, Jakschik BA, et al. Arachidanic acid metabolism. Annu Rev Biochem. 1986; 55:69-102.

34. Sakuradani E, Kobayashi M, Ashikari T, et al. Identification of Delta 12-fatty acid desaturase from arachidonic acid-producing Mortierella fungus by heterologous expression in the yeast Saccharomyces cerevisiae and the fungus Aspergillus oryzae. Eur J Biochem. 1999; 261(3):812-820.

35. Van Gool CJ, Thijs C, Henquet CJ, et al. Gamma-Linolenic acid supplementation for prophylaxis of atopic dermatitis-a randomized controlled trial in infants at high familial risk. Am J Clin Nutr 2003;77(4):943-951.

36. Sandberg A. Bioavailability of minerals in legumes. $\mathrm{Br} J$ Nutr. 2002;88:S281-285.

37. Towo E, Tatala S. Iron availability in weaning foods as affected by nutrient inhibitors. Food Nutr J. 1998;9:8-12.

38. Tako E, Glahn RP, Laparra JM, et al. Iron and Zinc Bioavailabilities to Pigs from Red and White Beans (Phaseolus vulgaris L.) are Similar. J Agric Food Chem. 2009;57(8):3134-3140.

39. Mawani M, Ali SA, Bano G. Iron Deficiency Anemia among Women of Reproductive Age, an Important Public Health Problem: Situation Analysis. Reprod Syst Sex Disord. 2016;5(3):1-6.

40. Singh P, Prasad S, Aalbersberg W. Bioavailability of Fe and Zn in selected legumes, cereals, meat and milk products consumed in Fiji. Food Chem. 2016;207:125-131.

41. Silva FG, Oliveira GL. Conhecimento popular e atividade antimicrobiana de Cydonia oblonga Miller (Rosaceae). Rev Bras Pl Med. 2013; 15(1):98103.

42. Ferreira TS, Moreira CZI, Cária NZ, et al. Phytotherapy: an introduction to its history, use and application. Rev Bras Pl Med. 2014;16(2):290-298.

43. Oliveira LAR, Machado RD, Rodrigues AJL, et al. Levantamento sobre o uso de plantas medicinais com a terapêutica anticâncer por pacientes da Unidade Oncológica de Anápolis. Rev Bras Pl Med. 2014;16(1):32-40.

44. Rochfort S, Panozzo J. Phytochemicals for health, the role of pulses. $J$ Agric Food Chem. 2007; 55(20):7981-7994.

45. Bouchenak M, Lamri-Senhadji M. Nutritional quality of legumes, and their role in cardiometabolic risk prevention: A review. J Med Food. 2013; 16(3):185-198.

46. Giusti F, Caprioli G, Ricciutelli M, et al. Determination of fourteen polyphenols in pulses by high performance liquid chromatographydiode array detection (HPLC-DAD) and correlation study with antioxidant activity and colour. Food Chem. 2015;221:689-697. 
47. Garcia-Lafuente A, Moro C, Manchón N, et al. In vitro anti- inflammatory activity of phenolic rich extracts from white and red common beans. Food Chem. 2014;161:216-223.

48. Xu BJ, Chang SKC. A comparative study on phenolic profiles and antioxidant activities of legumes as affected by extraction solvents. $J$ Food Sci. 2007;72(2):S159-166.

49. Amarowicz R, Troszyńska A, Baryłko-pikielna N, et al. Extracts of polyphenolics from legume seeds-correlation between their total antioxidant activity, total phenolics content, tannins content and astringency. J Food Lip. 2004;11(4):278-286.

50. Awika M, Rooney LW, Wu X, et al. Screening methods to measure antioxidant activity of sorghum (Sorghum bicolor) and sorghum products. J Agric Food Chem. 2003;51(23):6657-6662.

51. Messina M, McCaskill-Stevens W, Lampe JW. Addressing the soy and breast cancer relationship: Review, commentary, and workshop proceedings. J Natl Cancer Inst. 2006;98(18):1275-1284.

52. Ricketts ML, Moore DD, Banz WJ, et al. Molecular mechanisms of action of the soy isoflavones includes activation of promiscuous nuclear receptors. A review. J Nutr Biochem. 2005;16(6):321-330.

53. Bramley PM. Vitamin E (review). J Sci Food Agric. 2000;80(7):913-938.

54. Boschin G, Arnoldi A. Legumes are valuable sources of tocopherols. Food Chem. 2011;127(3):1199-1203.

55. Marathe SA, Rajalakshmi V, Jamdar SN, et al. Comparative study on antioxidant activity of different varieties of commonly consumed legumes in India. Food Chem Toxicol. 2011;49(9):2005-2012.

56. Padhi EMT, Ronghua Liu, Marta Hernandez, et al. Total polyphenol content, carotenoid, tocopherol and fatty acid composition of commonly consumed Canadian pulses and their contribution to antioxidant activity. $J$ Funct Foods. 2017;38(Part B):602-611.

57. Hoareau L, DaSilva EJ. Medicinal plants: A re-emerging health aid. Electronic J Biotechnol. 1999;2(2):79-87.

58. Cho SJ, Juillerat MA, Lee CH. Cholesterol lowering mechanism of soybean protein hydrosylate. J Agric Food Chem. 2007;55(26):10599-10604.

59. López A, El-Naggar T, Dueñas M, et al. Effect of cooking and germination on phenolic composition and biological properties of dark beans (Phaseolus vulgaris L.). Food Chem. 2013;138(1):547-555.

60. Aguilera Y, Martín-Cabrejas MA, González de Mejia E. Phenolic compounds in fruits and beverages consumed as part of mediterranean diet: their role in prevention of chronic diseases. Phytochem Rev. 2016;15(3):405-423.

61. Bazzano LHJ, et al. Legume consumption and risk of coronary heart disease in US men and women: NHANES I Epidemiologic Follow-up Study. Arch Intern Med. 2001;161(21):2573-2578.

62. Flight I, Clifton P. Cereal grains and legumes in the prevention of coronary heart disease and stroke: A review of the literature. Eur J Clin Nutr. 2006;60(10):1145-1159

63. Rimm EB, Willett WC, Hu FB, et al. Folate and Vitamin B6 from diet and supplements in relation to risk of coronary heart disease among women. JAMA. 1998;279(5):359-364.
64. YAO Y, Yang X, Tian J, et al. Antioxidant and antidiabetic activities of black mung bean (Vigna radiata L.). J Agric Food Chem. 2013;61(34):8104 8109.

65. Venn BJ, Mann JI. Cereal grains, legumes and diabetes. Eur J Clin Nutr. 2004;58(11):1443-1461.

66. Velie EM, Schairer C, Flood A, et al. Empirically derived dietary patterns and risk of postmenopausal breast cancer in a large prospective cohort study. Am J Clin Nutr. 2005;82(6):1308-1319.

67. Fung T, et al. Major dietary patterns and the risk of colorectal cancer in women. Arch Intern Med. 2003; 163:309-314.

68. Agurs-Collins T, Smoot D, Afful J, et al. Legume intake and reduced colorectal adenoma risk in African-Americans. JNBNA. 2006;17(2):6-12.

69. Luzzatto L, Annelli C, Notaro R. Glucose-6-phosphate dehydrogenase deficiency. Hematol Oncol Clin North Am. 2016;30(2):373-393.

70. Khalil MI, Salih MA, Mustafa AA. Study of fatty acid composition, physiochemical properties and thermal stability of broad beans (Vicia faba) seed oil. Agric Bio J N Am. 2017;8(4):141-146.

71. Stephens FO. Phytoestrogens and prostate cancer: Possible preventive role. Med J Aust. 1997;167(3):138-140.

72. Beck V, Unterrieder E, Krenn L, et al. Comparison of hormonal activity (estrogen, androgen and progestin) of standardized plant extracts for large scale use in hormone replacement therapy. J Steroid Biochem Mol Biol. 2003;84(2-3):259-268

73. Balandrin MF, Klocke JA, Wurtele ES, et al. Natural plant chemicals: Sources of industrial and medicinal materials. Science. 1985;228(4704):1154-1160.

74. Oniyangi O, Cohall DH. Phytomedicines (medicines derived from plants) for sickle cell disease. Cochrane Database Syst Rev. 2013.6(10):1-30.

75. Afolabi IS, Osikoya IO, Fajimi OD, et al. Solenostemon monostachyus, Ipomoea involucrata and Carica papaya seed oil versus Glutathione, or Vernonia amygdalina: methanolic extractsof novel plants for the management of sickle cell anemia disease. BMC Complement Altern Med. $2012 ; 12: 262$

76. Ferraz HG. Formas farmacêuticas sólidas: comprimidos e comprimidos revestidos. Brazil: Farm/USP Fac Ciênc; 2007. p. 1-9.

77. Daudt RM. Estudo das propriedades do amido do pinhão visando a sua utilização como excipiente farmacêutico. Dissertação (Mestrado) Universidade Federal do Rio Grande do Sul; 2012: 103 p.

78. Frota KMG, Morgano MA, Marta Gomes da Silva, et al. Utilização da farinha de feijão-caupi (Vignaunguiculata L. Walp) na elaboração de produtos de panificação. Ciên Tecnol Alim. 2009;30(1):44-50. 